are more stringent than the ordinary $\chi^{2}$ test since a further requirement is added that the numbers of particles in drops of identical size would be Poisson distributed.

Department of Scientific and

K. I. WILLIAMSON

Industrial Research,

Plant Chemistry Division.

Palmerston North,

New Zealand.

Meat and Wool Boards,

Wellington,

New Zealand.

' Williams, R. C., and Backus, R. C., J. Amer. Chem. Soc., 71, 4052 (1949).

${ }^{2}$ Backus, R. C., and Williams, R. C., J. App. Phys., 21, 11 (1950).

${ }^{3}$ Luria, S. F., Williams, R. C., and Backus, R. C., J. Bact., 61, 179 (1951).

"Williamson, K. I, and Taylor, W. B., Brit. J. App. Phys., 9, 264 (1958).

'Opfell, J. B., Nature, 186, 822 (1960).

'Watson, D. H., Biochim. Biophys. Acta, 61, 321 (1962).

"Bresse, jun., S. S., and Trautman, R., Virology, 10, 57 (1960).

Crocker T. T., and Bennett, B. M., J. Immunol., 69, 183 (1952).

\section{A Method of Calculating Net Assimilation Rate}

A USEFUL measure of the photosynthetic efficiency of plants is 'net assimilation rate' $(E)$ defined by Gregory ${ }^{1}$ as the rate of increase of dry weight $(W)$ per unit of leaf area $(L)$; that is:

$$
E=\frac{1}{L} \frac{\mathrm{d} W}{\mathrm{~d} t}
$$

In measuring $W$ the plant is destroyed, so changes in $W$ can be determined only by successive sampling from a population of plants, involving sampling errors. In practice samples are commonly taken at intervals of 1-4 weeks for measuring both $W$ and $L$. The paired $W$ and $L$ sample means may then be used to calculate $E_{M}$, an estimate of the mean $E$ for each time-interval $\left(t_{2}-t_{1}\right)$, usually as proposed by Gregory ${ }^{2}$ :

$$
E_{M}=\frac{\left(\bar{W}_{2}-\bar{W}_{1}\right)\left(\log _{e} \check{L_{2}}-\log _{e} \bar{L}_{1}\right)}{\left(t_{2}-t_{1}\right)\left(\bar{L}_{2}-\bar{L}_{1}\right)}
$$

Application of this formula to data recorded by one of us (J.C.S.A.) in an experiment on partial defoliation of maize gave the results shown in Table 1 .

$$
\begin{aligned}
& \text { Table 1. Mean Values of } E \text {.I (G/M } / \mathrm{M}^{3} / \text { WeEK) } \\
& \begin{array}{lcccc} 
& & \multicolumn{2}{c}{\text { Period in weeks after flowering }} \\
& 0-2 & 2-4 & 4-6 & 6-8 \\
\text { Control } & 42 \cdot 0 & 23 \cdot 5 & 33 \cdot 1 & 27 \cdot 8 \\
\text { Defoliated } & 43 \cdot 2 & 25.9 & 25 \cdot 3 & 36 \cdot 1 \\
\text { S.E. } & \pm 3 \cdot 8 & \pm 4 \cdot 2 & \pm 6 \cdot 1 & \pm 9 \cdot 3
\end{array}
\end{aligned}
$$

There were 6 plots of partially defoliated plants and 6 of controls. Samples of 9 plants were taken from each plot at fortnightly intervals $0-10$ weeks from flowering. The $L$ values at week 10 and hence the $E_{M}$ values for weeks 8-10 were unreliable because of the large number of senescent leaves, and have been omitted from Table 1. The standard errors are calculated from the variation between replicates.

The errors of Table 1 are large and the values fluctuate erratically, particularly in the later periods. This is because differences in $W$, which are subject to large errors, have to be taken and the errors of successive differences are negatively correlated.

It occurred to us that these errors might be greatly reduced by fitting smooth curves to $W$ and $L$, an approach which appears to have been overlooked by previous writers on this subject (see Watson ${ }^{3}$ for a review and bibliography).

In this experiment quadratic curves gave a satisfactory fit, as is shown by Fig. 1. The S.E.s of $W$ were calculated from the variation between replicates; this tended to increase with time but was reasonably homogeneous over

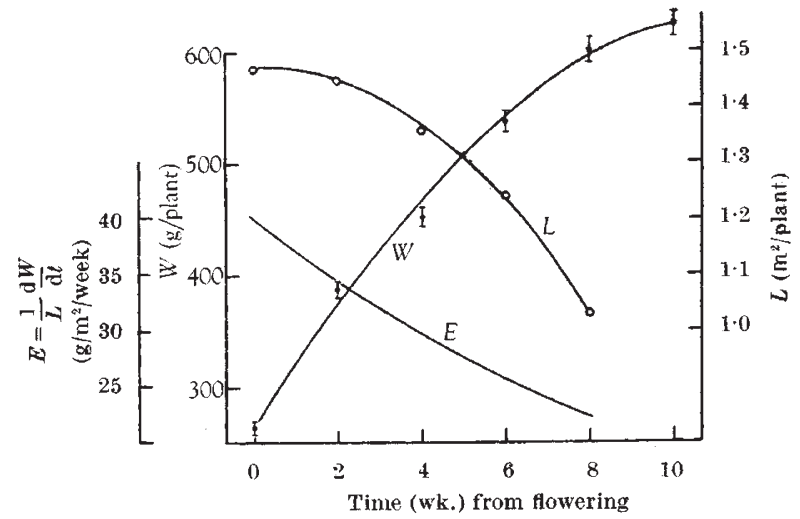

Fig. 1. Changes in dry weight $(W)$, leaf area $(L)$ and net assimilation rate $(E)$ of maize plants during 10 weeks following flowering

all dates after a $\log$ transformation. The S.E.s shown in Fig. 1 are the de-transformed values derived from the single pooled S.E. of $\log W$. In order to provide estimates of $E$ and their errors quadratic curves $W=a+b t+c t^{2}$ and $L=a^{\prime}+b^{\prime} t+c^{\prime} t^{2}$ were fitted to the $W$ values (including week 10 ) and the $L$ values (up to week 8) for each plot. separately. From (1) it follows that:

$$
E=\frac{b+2 c t}{a^{\prime}+b^{\prime} t+c^{\prime} t^{2}}
$$

This was evaluated for each plot for $t=0,1,2 \ldots 8$ weeks. The treatment means of the values for $t=1,3,5,7$ (the mid-points of the intervals used in Table 1) are shown in Table 2, and a graph of the mean $E$ of the control plots is included in Fig. 1.

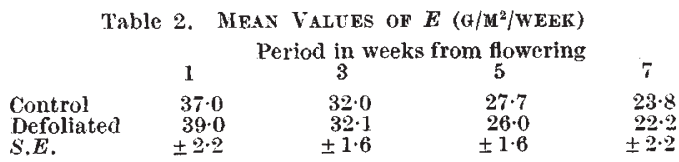

The results of Table 2 are much more regular than those of Table 1 , and the errors are much smaller. The values for the different times are not, of course, indepen. dent, but differences between treatments (for example, for average effect and rate of change) can be tested, in cases of doubt, by calculating the mean $(m)$ and regression coefficient $(b)$ of a suitable selection of calculated $E$ values for each plot and comparing the treatment mean $m$ and $b$ values. Thus we have:

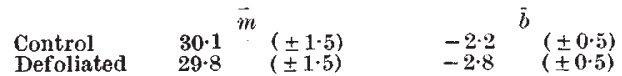

The general falling trend of $E$ with time is well established, and the absence of treatment effect is shown by the nonsignificance of $m$ and $b$ differences.

Inherent in the curve-fitting method is a smoothing out of any deviations from the general trend of $E$ with time. This loss is of no consequence here as the apparent deviations seen in the $E_{M}$ figures are of little statistical significance and, even if to some extent genuine, are irrelevant to the main purpose of the investigation.

The method is essentially empirical, and there is no necessity for the parameters of the curves to have biological significance, provided that the curves adequately describe the time changes of $W$ and $L$.

Statistics Department,

$$
\text { A. J. VERNON }
$$

Rothamsted Experimental Station.

$$
\text { J. C. S. Allison }
$$

Agricultural Department,

University College of Rhodesia and Nyasaland.

${ }^{1}$ Gregory, F. G., Third Ann. Rep. Exp. Res. Sta., Cheshunt, 19 (1917).

${ }^{2}$ Gregory, F. G., Ann. Bot., 40, 1 (1926).

${ }^{3}$ Watson, D. J., Advanc. Agron., 4, 101 (1952) 